\title{
La protección de datos en las aplicaciones móviles de diagnóstico de enfermedades genéticas. Un estudio jurídico
}

\section{Data protection in mobile diagnostic applications of genetic disease. A legal study}

\author{
Francisca Ramón Fernández
}

frarafer@urb.upv.es

\section{Profesora titular de Derecho civil. Universitat Politècnica de València}

\section{Resumen}

En el presente trabajo se realiza un análisis de los principales problemas jurídicos relativos a la protección de datos de carácter personal en el caso de las aplicaciones móviles de diagnóstico de enfermedades. El acceso a app por parte de consumidores que están interesados en la salud y diagnóstico puede provocar el hecho de que proporcionen información especialmente protegida, vulnerándose sus derechos. En la era de la denominada Internet de las cosas, el acceso ilimitado a la información contrasta con la necesidad de cumplir la legislación aplicable.

Palabras clave

Protección de Datos, Datos personales, Genética, Enfermedades, App.

\section{Abstract}

In the present work an analysis of the main legal problems regarding the protection of personal data in the case of the mobile applications of diagnosis of diseases is carried out. Access to the app on the part of consumers who are interested in health and diagnosis can provoke they give specially protected information, violating their rights. In the era of the so-called Internet of Things, unlimited access to information contrasts with the need to comply with applicable law.

\section{Keywords}

Data protection, Personal Data, Genetics, Disease, App.

Recibido: $22 / 05 / 2017$

Aceptado: $13 / 06 / 2017$

DOI: http://dx.doi.org/10.5557/IIMEI8-N14-005025

Descripción propuesta: RAMÓN FERNÁNDEZ, Francisca, 2017. La protección de datos en las aplicaciones móviles de diagnóstico de enfermedades genéticas. Un estudio jurídico. Métodos de Información, 8(14), pp. 5-25 


\section{Introducción}

Las Tecnologías de la Información y la Comunicación (TIC) se desarrollan en numerosos ámbitos y disciplinas. Uno de los campos en los que se ha desarrollado más la denominada Internet de las cosas (IoT, Internet of Things) es en las app, aplicaciones móviles (Martín 2017), en los Smartphone, en los que se puede descargar, bien de forma gratuita o previo pago, un innumerable catálogo de aplicaciones, entre ellas, las dedicadas al ámbito de la salud y médico.

En muchas ocasiones, el consumidor de estas aplicaciones (que puede ser un profesional o bien un profano en la materia) puede tener un claro desconocimiento de los datos que proporciona a la app, y es preciso establecer un sistema de garantías para evitar determinadas consecuencias en el caso de que el sujeto sea menor de edad, y que las aplicaciones estén relacionadas de forma directa con el diagnóstico de enfermedades, más aún si nos referimos a las genéticas. En realidad, estamos en presencia de un almacenamiento de numerosos datos, datos muy importantes ya que se relacionan con el padecimiento o no de una enfermedad, o incluso con la predisposición a padecerla y que, en caso de que a esos datos tuvieran acceso hackers, podrían ser utilizados con distintos fines (Lozoya, Villalba y Arias 2017).

En el presente trabajo nos proponemos acercarnos al tratamiento que en la legislación tienen los datos de carácter personal y las garantías de protección, incidiendo en el caso de los datos genéticos y los problemas de ámbito jurídico que se pueden plantear en el caso de las aplicaciones móviles de diagnóstico de enfermedades genéticas, que recientemente han sido objeto de noticia en distintos medios de comunicación.

\section{La protección de datos en la investigación biomédica}

La Ley 14/2007, de 3 de julio, de Investigación Biomédica (BOE núm. 159, de 4 de julio de 2007)(en adelante LIB) establece una serie de principios, pautas y procedimientos en relación con la obtención, tratamiento y utilización de los datos protegidos que se utilicen en el ámbito de la investigación biomédica.

Se ponen en relación varias normas, como son:

a) La Ley Orgánica 15/1999, de 13 de diciembre, de Protección de Datos de Carácter Personal (BOE núm. 298, de 14 de diciembre de 1999) (en adelante LOPD). 
b) La Ley 41/2002, de 14 de noviembre, básica reguladora de la autonomía del paciente $\mathrm{y}$ de derechos y obligaciones en materia de información y documentación clínica (BOE núm. 274, de 15 de noviembre de 2002), modificada por Ley 26/2015, de 28 de julio, de modificación del sistema de protección a la infancia y a la adolescencia (BOE núm. 180, de 29 de julio de 2015).

c) Real Decreto 1720/2007, de 21 de diciembre, por el que se aprueba el Reglamento de desarrollo de la Ley Orgánica 15/1999, de 13 de diciembre, de protección de datos de carácter personal (BOE núm. 17, de 19 de enero de 2008).

Y en el caso de la Comunitat Valenciana debemos indicar la aplicación de la Ley 10/2014, de 29 de diciembre, de Salud (BOE núm. 35, de 10 de febrero de 2015), que se remite a la normativa estatal en materia de protección de datos.

El tratamiento de los datos genéticos es especialmente sensible y se ponen en relación el principio de autonomía de la voluntad, la libertad en la prestación del consentimiento informado, y la obtención de la información, así como los derechos a no ser discriminado y a la confidencialidad en el caso de acceso a dichos datos, junto con la calidad, seguridad y trazabilidad de las muestras. La libertad de investigación, desde luego, no es absoluta, ya que está limitada por la dignidad e identidad personal y la protección de la salud humana. De ahí que el consentimiento informado, el derecho a la información, la protección de los datos y la confidencialidad estén relacionados entre sí, como puede verse en la Declaración Internacional sobre los Datos Genéticos Humanos, de 2003 (Cambrón 2004).

\section{Especial referencia a las enfermedades genéticas. Los denominados "datos especialmente protegidos"}

La LOPD, en su art. 7.3 se refiere a los datos especialmente protegidos, entre los que incluye los datos de carácter personal que hagan referencia a la salud, que sólo podrán ser recabados, tratados y cedidos en los casos que lo disponga una ley o bien el afectado lo consienta de forma expresa y no tácita, por razones de interés general. El art. 3 de la LOPD entiende que el consentimiento es "toda manifestación de voluntad, libre, inequívoca, específica e informada, mediante la que el interesado consienta el tratamiento de datos personales que le conciernen". 
El art. 7.6 LOPD indica que "podrán ser objeto de tratamiento los datos de carácter personal a que se refieren los apartados 2 y 3 de este artículo, cuando dicho tratamiento resulte necesario para la prevención o para el diagnóstico médicos, la prestación de asistencia sanitaria o tratamientos médicos o la gestión de servicios sanitarios, siempre que dicho tratamiento de datos se realice por un profesional sanitario sujeto al secreto profesional o por otra persona sujeta asimismo a una obligación equivalente de secreto" (Véase la postura del Tribunal Constitucional en Berrocal 2011).

El tratamiento legislativo de los datos referentes a la salud se contiene en el art. 8 LOPD en el que se remite al art. 11, que después veremos, y precisa que las instituciones y centros sanitarios, tanto públicos como privados, así como los profesionales de dichos ámbitos, podrán proceder al tratamiento de los datos referentes a la salud de las personas que a ellos acudan o tengan que tener un tratamiento en los mismos, de acuerdo con lo indicado en la legislación aplicable.

El art. 11 LOPD establece que los datos personales sólo podrán ser comunicados a un tercero para el cumplimiento de fines directamente relacionados con las funciones legítimas del cedente y cesionario, pero con el previo consentimiento del interesado. Se contempla la excepción de no ser preciso la prestación de dicho consentimiento en el caso de datos relativos a la salud, en el supuesto de que dicha cesión "sea necesaria para solucionar una urgencia que requiera acceder a un fichero o para realizar los estudios epidemiológicos en los términos establecidos en la legislación sobre sanidad estatal o autonómica".

$\mathrm{El}$ art. 33 LOPD respecto al movimiento internacional de datos preceptúa que se establece el principio de reciprocidad en cuanto a la seguridad del tratamiento de los datos, no pudiéndose realizar transferencias temporales ni definitivas de estos datos a países que no establezcan el mismo nivel de seguridad que el nuestro, con la excepción de la autorización de la Dirección de la Agencia Española de Protección de Datos, o bien esa transferencia sea precisa para la prevención o diagnóstico médico, prestación o tratamiento médico o gestión de servicios sanitarios.

La LIBhace referencia, en su art. 3, a "dato genético de carácter personal" que es considerado toda información acerca de las características hereditarias, identificada o identificable que se haya obtenido por análisis de ácidos nucleicos u otros análisis científicos. Precisa más la definición la Ley 11/2007, de 26 de noviembre, reguladora del Consejo Genético, de protección de los 
derechos de las personas que se sometan a análisis genéticos y de los bancos de ADN humano en Andalucía (BOE núm. 38, de 13 de febrero de 2008), que indica que se considera como tal la información sobre las características genéticas de un sujeto identificado o identificable obtenida mediante un análisis genético.

Se considera como "tratamiento de datos genéticos de carácter personal o de muestras biológicas", las operaciones y procedimientos para obtener, conservar, utilizar y ceder los datos genéticos personales o muestra biológicas. La doctrina ha puesto de manifiesto que: "La anonimización consiste en desvincular la información personal del individuo, de manera que dificulte, en la medida de lo posible, el proceso de reidentificación. La legislación española relativa a protección de datos, a diferencia de la de otros países, no contempla los datos médicos que deben ser anonimizados por ser considerados de nivel alto $(\ldots)$

Esto dificulta en gran medida un proceso ya de por sí complejo. Una opción que se podría plantear en relación a qué campos anonimizar, podría ser la realización de una anonimización del conjunto completo de los atributos clínicos, sin embargo, esto podría derivar en una pérdida de información relevante a la hora de extraer conocimiento de los datos recogidos de los pacientes. Por este motivo es necesario realizar una correcta elección de los datos que deben ser anonimizados, de manera que se pueda extraer conocimiento de los mismos garantizando el derecho a la protección de datos del paciente" (Lozoya, Villalba y Arias 2017, p. 2).

Se recoge el derecho a la información o su decisión de no ser informada, ya que cualquier persona puede ser informada acerca de sus datos genéticos obtenidos durante una investigación biomédica o haya aportado muestras biológicas.

El art. 5 LIB expresa que se garantizará la protección de la intimidad personal y el tratamiento confidencial de los datos, según la LOPD. La cesión de datos a terceros ajenos requerirá el consentimiento expreso y por escrito, y si se contienen datos de familiares, el de todos ellos.

Está prohibido utilizar los datos referentes a la salud de las personas con una finalidad diferente a la que se prestó el consentimiento.

Las personas que participen en una investigación biomédica están sometidas al deber de secreto, en cuanto que accedan a datos personales, incluso después de cesar la investigación. 
Respecto a los límites de los análisis genéticos, el art. 9 LIB, asegura la protección de los derechos de las personas y el tratamiento de datos genéticos en estos casos, que se deberán llevar a cabo dichos análisis con criterios de pertinencia, calidad, equidad y accesibilidad (aplicándose también lo indicado en el art. 45 LIB).

Solamente se permiten hacerse pruebas predictivas de enfermedades genéticas o identificatorias de portar un gen o tener una predisposición, con fines médicos de investigación, cuando esté indicado, o en el caso del estudio de las diferencias inter-individuales en la respuesta a los fármacos, o para estudiar las bases moleculares de las patologías.

El tratamiento de datos genéticos de carácter personal se contempla, además, en los arts. 46 y sigs. LIB. Antes de la prestación del consentimiento, el sujeto deberá ser informado por escrito acerca de la finalidad del análisis genético, dónde se va a realizar, quiénes tendrán acceso a los resultados en el caso de que no sean sometidos a anonimización, las consecuencias de tener información inesperada y efectos para la familia, y compromiso de suministrar consejo genético después de obtenidos y evaluados los resultados.

El art. 48 LIB establece que será preciso el consentimiento expreso y por escrito para la realización del análisis genético, y el art. 49 LIB el derecho a la información y a no ser informado, teniendo en cuenta el derecho de acceso de la LOPD.

El acceso a los datos genéticos por parte del personal sanitario se establece en el art. 50 LIB. Tendrán acceso los profesionales sanitarios del centro o establecimiento en el que se conserve la historia clínica del paciente en tanto sea pertinente para la asistencia que presten al paciente, pero están sujetos al cumplimiento de los derechos de reserva y confidencialidad.

En el caso de que se utilicen los datos genéticos de carácter personal para fines epidemiológicos, de salud pública, investigación o docencia, el sujeto deberá haber prestado de forma expresa su consentimiento, o bien los datos estén anonimizados, de forma que no se pueda conocer la identidad del mismo, salvo la excepción contemplada en el art. 50.3 LIB.

Se establece el deber de secreto del personal que acceda a datos genéticos en su actividad profesional, necesitando el consentimiento expreso y escrito de la persona para poderlos revelar a terceros, según indica el art. 51 LIB. En el caso de que el sujeto sea menor se dará la información a los tutores o representantes legales. 
La conservación de los datos protegidos será como mínimo durante cinco años, desde su obtención. Después, el interesado podrá solicitar que se cancelen.

También están sujetos a protección de datos los obtenidos en análisis genéticos realizados en material embrionario o fetal (art. 53 LIB).

En los casos de cribado genético, el art. 54 LIB establece los requisitos y la protección de datos de los resultados obtenidos, tal y como hemos indicado para los análisis genéticos.

Real Decreto-ley 9/2014, de 4 de julio, por el que se establecen las normas de calidad y seguridad para la donación, la obtención, la evaluación, el procesamiento, la preservación, el almacenamiento y la distribución de células y tejidos humanos y se aprueban las normas de coordinación y funcionamiento para su uso en humanos (BOE núm. 163, de 5 de julio de 2014), en su art. 6 establece el régimen de confidencialidad de los datos relacionados con la salud de los donantes que se faciliten, en aplicación de la normativa de protección de datos anteriormente referida. Ello tiene un límite en el caso de que ese deber de confidencialidad no puede impedir adoptar medidas de prevención o cautelares en el caso de sospecha de riesgo para la salud individual o colectiva, conforme a lo indicado en los arts. 25 y sigs. de la Ley 14/1986, de 25 de abril, General de Sanidad (BOE núm. 102, de 29 de abril de 1986) y la Ley Orgánica 3/1986, de 14 de abril, de medidas especiales en materia de salud pública (BOE núm. 102, de 29 de abril de 1986). De conformidad con este principio, no se podrá facilitar información para la identificar a los donantes y receptores de células y tejidos humanos. Esta confidencialidad está íntimamente relacionada con la protección de datos de carácter personal (Ramón 2013).

\section{Las aplicaciones móviles de diagnóstico. El caso de los menores: el interés superior}

A raíz de la aparición en distintos medios de comunicación de la noticia de la existencia de una app que ayuda al diagnóstico de enfermedades raras, se 
plantean diversos problemas jurídicos en relación con la protección de datos, menores y prestación del consentimiento y la utilización de las imágenes para la detección.

Como indica el Real Decreto 1091/2015, de 4 de diciembre, por el que se crea y regula el Registro Estatal de Enfermedades Raras (BOE núm. 307, de 24 de diciembre de 2015) se consideran como enfermedades raras o poco frecuentes las que, con peligro de muerte o invalidez crónica, afectan a menos de 5 casos por cada 10.000 habitantes. Pueden aparecer en la infancia o en la edad adulta y constituyen un problema para su detección y tratamiento, siendo un objetivo prioritario para la acción de la Unión Europea aumentar su visibilidad y mejorar su reconocimiento.

La recomendación del Consejo, de 8 de junio de 2009, relativa a una acción en el ámbito de las enfermedades raras establece una serie de estrategias y planes en el ámbito de estas enfermedades:

«Elaborar y aplicar planes o estrategias para las enfermedades raras en el nivel adecuado, o bien estudiar las medidas adecuadas para las enfermedades raras en otras estrategias de sanidad pública, para tratar de garantizar que los pacientes de enfermedades raras tengan acceso a una asistencia sanitaria de alta calidad, que incluya el diagnóstico, el tratamiento, la habilitación para las personas que padecen la enfermedad y, de ser posible, medicamentos huérfanos eficaces, y en particular:

a) elaborar y adoptar un plan o una estrategia lo antes posible, preferentemente a finales de 2013 a más tardar, para gestionar y estructurar todas las acciones pertinentes en materia de enfermedades raras en el marco de sus sistemas sanitarios y sociales;

b) actuar para integrar las iniciativas actuales y futuras de nivel local, regional y nacional en sus planes o estrategias, para obtener una visión general;

c) definir un número reducido de actuaciones prioritarias dentro de sus planes o estrategias, con unos objetivos y unos mecanismos de seguimiento;

d) tomar nota de la elaboración de directrices y recomendaciones para definir la acción nacional en materia de enfermedades raras por parte de las autoridades competentes a escala nacional en el marco del Proyecto Europeo de Elaboración de Planes Nacionales de Enfermedades Raras (EUROPLAN) actualmente en curso, seleccionado para recibir 
financiación durante el período 2008-10 en el marco del primer

Programa de acción comunitario en el ámbito de la salud pública».

Y recomienda a los Estados miembros:

«tratar de garantizar que las enfermedades raras tengan una codificación y trazabilidad apropiadas en todos los sistemas de información sanitarios, para favorecer un reconocimiento adecuado de dichas enfermedades en los sistemas nacionales de asistencia sanitaria y de reembolso basado en la Clasificación Internacional de Enfermedades dentro del respeto de los procedimientos nacionales».

La Estrategia en Enfermedades Raras del Sistema Nacional de Salud Actualización aprobada por el Consejo Interterritorial del Sistema Nacional de Salud el 11 de junio de 2014, del Ministerio de Sanidad, Servicios Sociales e Igualdad indica la problemática que se refiere a las enfermedades raras (EERR):

«-La dificultad de decidir si una determinada enfermedad debe ser clasificada o no, como enfermedad rara, porque los criterios utilizados no siempre son aceptados universalmente.

-La terminología médica al uso es muy variada, lo que hace que la relación de entidades nosológicas y sus respectivos sinónimos sea muy abigarrada e introduzca un elemento de confusión en cualquier clasificación.

-Algunas de estas enfermedades tienen una etiología multifactorial y muchas de ellas afectan a diversos órganos y sistemas, por lo que en ocasiones es difícil ubicarlas en un grupo determinado de enfermedades.

-El ritmo de identificación de nuevas enfermedades y de nuevos grupos de enfermedades es tan acelerado en algunos terrenos (por ejemplo errores congénitos del metabolismo, tumores, etc.) que hace que continuamente se añadan a los listados alfabéticos de EERR nuevas entidades en búsqueda del sitio que les corresponde.

-La dificultad en el diagnóstico definitivo de algunas EERR y su agrupación en familias de enfermedades».

El Registro regulado en la norma mencionada tiene una triple finalidad: tanto proporcionar información epidemiológica sobre estas enfermedades, así como orientar la planificación, gestión y evaluación de las actividades de prevención y asistencia, y proveer los indicadores básicos sobre las mismas para establecer una comparación a nivel nacional e internacional. El registro cumplirá las 
medidas de seguridad establecidas en la Ley 11/2007, de 22 de junio, de acceso electrónico de los ciudadanos a los Servicios Públicos (BOE núm. 150, de 23 de junio de 2007), actualmente derogado por la Ley 39/2015, de 1 de octubre, del Procedimiento Administrativo Común de las Administraciones Públicas (BOE núm. 236, de 2 de octubre de 2015)y en el Real Decreto 3/2010, de 8 de enero, por el que se regula el Esquema Nacional de Seguridad en el ámbito de la Administración Electrónica (BOE núm. 25, de 29 de enero de 2010), modificada por Real Decreto 951/2015, de 23 de octubre (BOE núm. 264, de 4 de noviembre de 2015).

Por último la Ley 33/2011, de 4 de octubre, General de Salud Pública (BOE núm. 240, de 5 de octubre de 2011), que modifica la Ley 16/2003, de 28 de mayo, de Cohesión y Calidad del Sistema Nacional de Salud (BOE núm. 128, de 29 de mayo de 2003), en el que se indica que la prestación de salud pública tiene como una de sus actuaciones la prevención y detección precoz de las enfermedades raras, así como el apoyo a los que la padecen y sus familias.

Teniendo en cuenta que estas aplicaciones móviles (por ejemplo, la conocida como face2gene, Smart phenotyping. Better genetics) que han proliferado actualmente y que algunas pueden ser utilizadas por cualquier persona y no sólo por el profesional médico, plantean distintas cuestiones en relación con la protección de datos y los sujetos protegidos, ya que no hay que olvidar que algunas de ellas están destinadas a la detección de enfermedades genéticas en menores de edad. Tendríamos que partir de varias premisas para su análisis jurídico:

a) Las app tienen que tener disponible una gran cantidad de datos que pueden estar protegidos. El tema de las imágenes como soporte para el diagnóstico plantea cuestiones en el caso de la prestación del consentimiento por parte del menor de edad (Cfr. Plaza 2008; Pérez 2009; Vázquez 2012; Guillén 2015; Fernández 2016; Sánchez 2017), ya que no se trata de retratos robot, sino de imágenes de personas con determinadas patologías y características fisonómicas para la detección de una enfermedad genética, por semejanza con la imagen. Ello plantearía, además, los derechos de autor de las fotografías en cuanto a su protección (Hernández y Ramón 2009; Ramón 2013) por la legislación de propiedad intelectual, en concreto por aplicación del Real Decreto Legislativo 1/1996, de 12 de abril, por el que se aprueba el texto refundido de la Ley de Propiedad Intelectual, regularizando, aclarando y armonizando las disposiciones legales vigentes sobre la materia (BOE núm. 97, de 22 de abril de 1996). 
b) La reutilización de la información contenida en las aplicaciones móviles (Cfr. Troncoso 2009).No se aplicaría lo indicado, por estar expresamente excluido, en la Ley 37/2007, de 16 de noviembre, sobre reutilización de la información del sector público (BOE núm. 276, de 17 de noviembre de 2007), modificada por Ley 18/2015, de 9 de julio (BOE núm. 164, de 10 de julio de 2015).

b) En el caso de las aplicaciones móviles destinadas a menores habría que tener en cuenta el interés superior del menor, respecto a la prestación del consentimiento para la utilización de la misma, en los supuestos en los que pueda ser oído y escuchado, teniendo en cuenta los casos de discapacidad, de conformidad con lo indicado en el art. 2 de la Ley Orgánica 1/1996, de 15 de enero, de Protección Jurídica del Menor, de modificación parcial del Código civil y de la Ley de Enjuiciamiento Civil (BOE núm. 15, de 17 de enero de 1996), modificada por Ley Orgánica 8/2015, de 22 de julio, de modificación del sistema de protección a la infancia y a la adolescencia (BOE núm. 175, de 23 de julio de 2015).

c) La problemática en cuanto a las denominadas patentes de invenciones implementadas en ordenador (Oficina Española de Patentes y Marcas, 2017), teniendo en cuenta lo indicado en la Ley 24/2015, de 24 de julio, de Patentes (BOE núm. 177, de 25 de julio de 2015) y Real Decreto 316/2017, de 31 de marzo, por el que se aprueba el Reglamento para la ejecución de la Ley 24/2015, de 24 de julio, de Patentes (BOE núm. 78, de 1 de abril de 2017), respecto a que no se consideran invenciones los programas de ordenadores, que gozan de la protección que el Real Decreto Legislativo 1/1996 concede como derecho de autor sobre los mismos, pero sí que puede ser objeto de patente una invención que se pueda implementar en el ordenador, y que el programa de ordenador puede formar parte de una patente, con lo que se le aplicará el régimen de la propiedad industrial. Ello puede suceder en el caso de lo que indica la Oficina Española de Patentes y Marcas como "uso de tecnología de imaginería médica". De ahí la relación también con la aplicación industrial y el mundo de la empresa (Canós, Ramón y Mauri 2007 y 2008).

d) La realización de ensayos clínicos con medicamentos en los que participe lo que se denomine un producto sanitario, entre los que se puede incluir un programa informático de diagnóstico, tal y como preceptúa el Real Decreto 1090/2015, de 4 de diciembre, por el que se regulan los ensayos clínicos con medicamentos, los Comités de Ética de la investigación con medicamentos y 
el Registro Español de Estudios Clínicos (BOE núm. 307, de 24 de diciembre de 2015).

En el caso de face2gene se trata de una app de reconocimiento facial (Cárdenas 2017) que se basa en la identificación de la denominada dismorfología con la finalidad de determinar qué enfermedad padece el sujeto. Las dificultades para la identificación en situación normal, es decir, sin el uso de la app se basa en que no hay una clasificación amplia de las enfermedades raras, y no se dispone de una base de intercambio de datos y muestras.

La existencia de mutaciones genéticas hace que sea poco rápida la detección mediante un sistema de análisis, y la app intenta solucionar este problema mediante el cotejo de patrones. La app se sirve de fotografías y la utilización de un algoritmo matemático, para determinar la cantidad de coincidencias en los síndromes. Sin embargo, hay que señalar que consideramos que esta aplicación es un instrumento, una herramienta más a disposición del facultativo que, junto con otras pruebas médicas, permita la identificación de la enfermedad.

También es preciso apuntar que la app tiene que disponer de una gran cantidad de datos, de imágenes, para que se puedan contrastar los rasgos de un paciente con los que sufren una enfermedad semejante, para que el algoritmo resultante sea lo más fiable posible.

Se plantean problemas en cuanto al almacenamiento de datos en la aplicación, que serán datos protegidos con lo que hay que tener en cuenta lo indicado en la normativa de referencia. Pero, además, hay que añadir que al utilizarse fotografías habrá que tener en cuenta lo dispuesto en la normativa de propiedad intelectual, y aún más, en el caso de que el sujeto de la imagen sea un menor, la prestación del consentimiento, así como el interés superior del mismo.

Junto con esta reflexión, la app también nos llama la atención, desde el punto de vista jurídico, respecto a si se puede considerar como un método de diagnóstico en sí, ya que la noticia habla de que lo que se pretende es que sea accesible y que constituya una ayuda para los médicos. De ahí que habría que tener en cuenta si la app sólo está disponible para los facultativos, y sería bajo su supervisión, y que no pudiera ser utilizada por cualquier persona, ya que podría hacer un uso no correcto de la información.

Se produce, pues, indefensión por parte del consumidor de estas aplicaciones, ya que ignoran la información personal que están compartiendo, y que no 
disponen de los derechos ARCO (acceso, rectificación, cancelación y oposición) que establece la LOPD.

Otra noticia similar la podemos encontrar respecto a la existencia de un software para ayudar a los médicos a diagnosticar enfermedades genéticas, siendo la herramienta fácil y sin costes. Esta herramienta denominada Mendel, DM (Agencia Iberoamericana para la difusión de la ciencia y la tecnología 2017) puede analizar el genoma en su totalidad o secuencia y proporcionar una lista de mutaciones.

En la noticia se indica que es también para ayudar a los médicos para el análisis de los datos de los pacientes para diagnóstico de enfermedades generadas a causa de una mutación genética.

Parece que el acceso es sólo para personal médico, ya que se tiene que subir a la aplicación de la web el genoma o su secuencia, por lo que sería de difícil cumplimentación para un paciente que no dispone de dichos datos.

Sin embargo, aquí nos surge el mismo problema, no sabemos si la aplicación solicita datos personales del paciente, y, en todo caso almacena una gran cantidad de datos sensibles para realizar la computación y el contraste de los mismos, ya que entonces tenemos la misma situación, son datos protegidos y se tendría que aplicar la normativa en materia de protección de datos de carácter personal. Aquí, en este caso no se utilizarían fotografías, a diferencia de la aplicación anterior.

Otros ejemplos los tenemos en las denominadas "herramientas de prevención". En este caso vamos a indicar la denominada Patia-Diabetes Prevent. Como indica la propia aplicación, dispone de test genético y aplicaciones para medir el riesgo y poner remedios, en el caso de que aquél sea alto de padecer la diabetes tipo 2 .

Otro problema jurídico que se plantea es que, el consumidor de este tipo de productos con un perfil hipocondriaco, y que igual se descarga una app para medir su riesgo de diabetes, de ataque cardiaco, enfermedades degenerativas, cáncer, etc. (algo similar puede suceder con la consulta de las numerosas webs que existen sobre patologías, síntomas de enfermedades, etc., y que derivan en una confusión de quienes las consultan), al no disponer de formación médica no puede prever las consecuencias que se pueden derivar de obtener una información que no sea correcta o que la haya malinterpretado.

Cada vez son más los casos de pacientes que acuden al médico diciendo que sospechan que sufren tal o cual enfermedad porque "lo han consultado en internet", con lo que con la existencia de app disponibles y al alcance de 
cualquier usuario, puede causar un efecto similar: acudir al médico e indicarle que sufre tal patología, porque se lo ha diagnostico la app de turno o se ha hecho un chequeo "por internet" en el que un "médico" le ha dicho tal o cual cosa (Gayá 2016).

Si bien, todo ello parece fruto de ciencia-ficción, no estamos desencaminados, ya que si repasamos la producción cinematográfica más reciente, encontramos, que en un futuro podremos ser diagnosticados (y curados) por máquinas. Un ejemplo lo podemos encontrar en la película Passengers (2016), dirigida por Morten Tyldum, con guión de Jon Spaihts, en la que varios protagonistas que padecen distintas patologías son introducidos en cápsulas y la máquina diagnostica, y "repara" los cuerpos.

\section{Conclusiones}

El acceso actual a numerosas aplicaciones móviles relacionadas con la salud del individuo plantea, en el ámbito jurídico, diversas cuestiones en relación con los datos personales que se proporcionan para la utilización de las mismas. No solamente es interesante destacar la necesidad de proteger los datos, sino también el resultado que se obtiene en el análisis de determinados aspectos relacionados con el individuo, como es el ámbito genético.

Disponemos de una legislación adecuada en materia de protección de datos de carácter personal; pero eso no significa que no le encontremos fisuras en la aplicación de la misma. En el caso del almacenamiento de datos para que una determinada app funcione con la detección de determinada enfermedad, se plantean numerosos problemas, no siempre con una solución jurídica ad hoc.

Uno de los problemas es la utilización de las fotografías como herramienta para diagnosticar una enfermedad genética, principalmente en los niños (Gómez-Juárez 2006; Sánchez 2009), que plantea utilizar una imagen protegida y todas las consecuencias de rastreo de datos después de su almacenamiento.

En la época del Internet de las cosas, en la que todos estamos digitalizados y en la que los smartphones forman parte prácticamente inseparable de nuestro cuerpo físico, ya que estamos en una permanente conexión, ya sea para mensajería instantánea, consultar el correo electrónico, y cómo no, descargarnos aplicaciones diversas, ya por curiosidad o entretenimiento.

Dentro de estas app destacan las numerosas que tienen relación con la salud del ser humano (toma de tensión, pulsómetro, test variados de predicción de sufrir una determinada enfermedad, ...), que han ganado popularidad entre 
los usuarios porque son de libre acceso y gratuitas, de manera la que la mayoría de las personas tienen instalada alguna o algunas.

Todos los datos que proporcionamos tenemos que ser conscientes de que pueden ser de carácter personal, y que nos ampara la LOPD (cfr. Guzmán 2015).

Si vamos más allá y estas aplicaciones son utilizadas por profesionales de la salud, nos encontramos con que también tenemos que estar protegidos, ya que esas aplicaciones se nutren del cotejo de numerosos datos obtenidos de otras tantas personas que los han proporcionado, para hacer un diagnóstico más fiable y seguro. Pero, nos podemos preguntar ¿estamos realmente protegidos y nuestros datos van a ser correctamente utilizados? La respuesta no podemos contestarla de forma positiva, porque son numerosos los interrogantes que nos suscita una reflexión de esta nueva época, en la que las TIC están presenten en todos los actos de nuestra vida.

\section{Agradecimientos}

Proyecto I+D Excelencia MINECO DER2015-65810-P (2016-2018). El avance del Gobierno Abierto. Régimen jurídico constitucional de la implantación de políticas de datos abiertos, colaboración y participación especialmente a través de las TIC y del gobierno electrónico. Investigador Principal el Dr. D. Lorenzo Cotino Hueso, Catedrático acreditado de Derecho constitucional, Universitat de València-Estudi General, del Microcluster "Estudios de Derecho y empresa sobre TICs (Law and business studies on ICT)", dentro del VLC/Campus, Campus de Excelencia Internacional (International Campus of Excellence), coordinado por el Dr. D. Javier Plaza Penadés, Catedrático de Derecho civil, Universitat de València-Estudi General, y Proyecto "Derecho civil valenciano y europeo" del Programa Prometeo para Grupos de Investigación de Excelencia de la Conselleria de Educación, Cultura y Deporte, GVPROMETEOII2015-014.

\section{Bibliografía}

AGENCIA IBEROAMERICANA PARA LA DIFUSIÓN DE LA CIENCIA Y LA TECNOLOGÍA, 2017. Un software de fácil uso y gratuito para ayudar a los médicos a diagnosticar enfermedades genéticas. [Consulta: 16 junio 2017]. Disponible en: http://www.dicyt.com/viewNews.php?newsId=37312 
BERROCAL LANZAROT, A. I., 2011. La protección de datos relativos a la salud y la historia clínica. Revista de la Escuela de Medicina Legal, 18, 11-44. ISSN 18859577 [Consulta: 16 junio 2017]. Disponible en:

http://pendientedemigracion.ucm.es/centros/cont/descargas/documento30950.pd $\underline{\mathrm{f}}$

CAMBRÓN INFANTE, A., 2004. Los principios de protección de datos genéticos y la declaración de la UNESCO. Anuario da Facultade de Dereito da Universidade da Coruña, 8, 209-222. ISSN 1138-039X [Consulta: 16 junio 2017]. Disponible en:http://ruc.udc.es/dspace/handle/2183/2338

CANÓS DARÓS, L., RAMÓN FERNÁNDEZ, F. y MAURI CASTELLÓ, J. J., 2007. La protección de datos personales y la información para la gestión del conocimiento en las empresas. Revista General Informática de Derecho, 1-8. ISSN0210-0401

CANÓS DARÓS, L., RAMÓN FERNÁNDEZ, F. y MAURI CASTELLÓ, J. J., 2008. Aspectos jurídicos y económicos de la propiedad industrial de la empresa. Novática, 193, 56-58. ISSN 0211-2124

CÁRDENAS, F., 2017. Face2gene. La app que ayudará a diagnosticar enfermedades raras. El Observador. [Consulta: 16 junio 2017]. Disponible en: https://elobservadormexico.com/tecnologia/face2gene-la-app-que-ayudaraa-diagnosticar-enfermedades-raras/

FACE2GENE. SMART PHENOTYPING. BETTER GENETICS. [Consulta: 14junio 2017]. Disponible en: https:// suite.face2gene.com/

FERNÁNDEZ PÉREZ, A., 2016. La protección de los derechos fundamentales de los menores en Internet desde la perspectiva europea. Ius et Praxis, 22 (1), 377-416. ISSN 0717-2877 [Consulta: 18 junio 2017]. Disponible en: http://www.scielo.cl/pdf/iusetp/v22n1/art11.pdf

GAYÁ, V., 2016. El internet de las cosas ante el reto de la privacidad: Los ingresos por hardware y conectividad crecen a un 10-20 por ciento anual. El siglo de Europa, 1137, 44-45. ISSN 2254-9234 [Consulta: 16 junio 2017]. Disponible en:

http:/ / www.elsiglodeuropa.es/siglo/historico/2016/1137/1137Tiemposdeh oy.pdf

GÓMEZ-JUÁREZ SIDERA, J., 2006. Reflexiones sobre el derecho a la protección de los menores de edad y la necesidad de su regulación específica en la legislación española. Revista Aranzadi de derecho y nuevas tecnologías, 11, 71-88. ISSN 1696-0351

GUILLÉN CATALÁN, R., 2015. Los retos de la sociedad ante la protección de datos de los menores. Revista Boliviana de Derecho, 20, 324-343. ISNN-e 20708157 [Consulta: 16 junio 2017]. Disponible 
en:http://www.revistabolivianadederecho.com/index.php/rbd/revistadigital-pdf/send/2-nuestras-publicaciones-revista-rbd/631-revista-rbd-n-20

GUZMÁN GARCÍA, $\mathrm{M}^{\mathrm{a}}$ de los A., 2015. Retos actuales de los derechos privacidad y protección de datos personales, especial referencia a menores. En: J.V. GIMENO SENDRA y $\mathrm{M}^{\mathrm{a}}$. T. REGUEIRO GARCÍA coord. Nuevas tendencias en la interpretación de los derechos fundamentales. Madrid: Universitas, pp. 121-132. ISBN 978-8479914257

HEALTH 2.0 BASQUE, 2017. Patia-Diabetes Prevent: Herramientas para la prevención de la diabetes tipo 2. [Consulta: 16 junio 2017]. Disponible en: http://www.health20basque.com/2017/06/patia-diabetes-preventherramientas-para-la-prevencion-de-la-diabetes-tipo-2-en-health-2-0-basque/ HERNÁNDEZ FERNÁNDEZ, A. y RAMÓN FERNÁNDEZ, F., 2009. El derecho a la propia imagen de los menores en los medios de comunicación y redes sociales. Revista Aranzadi de Derecho y Nuevas Tecnologias, 20, 19-36. ISSN 1696-0351

LOZOYA DE DIEGO, A., VILLALBA DE BENITO, Mª T. y ARIAS POU, M., 2017. Taxonomía de información personal de salud para garantizar la privacidad de los individuos. El profesional de la información, 26 (2), 293-302. ISSN 1386-6710 [Consulta: 16 junio 2017]. Disponible en: http://www.elprofesionaldelainformacion.com/contenidos/2017/mar/16.p df

MARTÍN GARCÍA, E., 2017. Internet de las cosas: ¿dónde queda la seguridad de las personas?. Red seguridad: revista especializada en seguridad informática, protección de datos y comunicaciones, 76, 42-44. ISSN 1695-3991 [Consulta: 16 junio 2017]. Disponible en: http://www.redseguridad.com/revistas/red/076/files/assets/basichtml/page-42.html

MENDEL, MD. [Consulta: 16 junio 2017]. Disponible en: https://www.mendelmd.org/

MINISTERIO DE SANIDAD, SERVICIOS SOCIALES E IGUALDAD., 2013. Estrategia en Enfermedades Raras del Sistema Nacional de Salud. Actualización aprobada por el Consejo Interterritorial del Sistema Nacional de Salud el 11 de junio de 2014. Madrid. [Consulta: 19 junio 2017]. Disponible en: http://www.europlanproject.eu/_europlanproject/Resources/docs/NATIO NALPLANS_SPAIN_Update2014_spanish\%28e\%29.pdf

OFICINA ESPAÑOLA DE PATENTES Y MARCAS, 2017. ¿Patentar software?. Normas y usos en la Oficina Europea de Patentes. [Consulta: 14 junio 2017]. Disponible en: http://www.oepm.es/cs/OEPMSite/contenidos/Folletos/FOLLETO 3 P ATENTAR SOFTWARE/017-12 EPO software web.html 
PASSENGERS, 2016. [Consulta: 14 junio 2017]. Disponible en: https://www.filmaffinity.com/es/film478232.html

PÉREZ LUÑO, A. E., 2009. La protección de los datos personales del menor en Internet. Anuario de la Facultad de Derecho, 2, 143-175. ISSN-e 1697-5723 [Consulta: 18 junio 2017]. Disponible en: http://dspace.uah.es/dspace/handle/10017/6441

PLAZA PENADÉS, J., 2008. El derecho de protección de datos de los menores en la Comunitat Valenciana. Revista de derecho civil valenciano, 4, 1-3. ISSN 8861490 [Consulta: 18 junio 2017]. Disponible en: http://www.derechocivilvalenciano.com/revista/numeros/4-segundosemestre-2008/item/10-el-derecho-de-proteccion-de-datos-de-los-menoresen-la-comunitat-valenciana

RAMÓN FERNÁNDEZ, F., 2013. La protección de los derechos de autor de las fotografías y la prestación del consentimiento. Revista Aranzadi de derecho y nuevas tecnologías, 31, 47-74. ISSN 1696-0351

RAMÓN FERNÁNDEZ, F., 2014. La mediación electrónica, la confidencialidad y la protección de datos de carácter personal. InDret. Revista para el análisis del Derecho, 3, 1-28. ISSN 1698-739X. [Consulta: 16 junio 2017]. Disponible en: http://www.indret.com/es/?a=14

SÁNCHEZ CARAZO, C., 2009. La protección de datos personales de las personas vulnerables. Anuario de la Facultad de Derecho, 2, 203-227. ISSN-e 1697-5723 [Consulta: 19 junio 2017]. Disponible en: http://dspace.uah.es/dspace/handle/10017/6443

SÁNCHEZ GÓMEZ, A., 2017. Las nuevas tecnologías y su impacto en los derechos al honor, intimidad, imagen y protección de datos del menor. Mecanismos jurídicos de protección: Carencias, interrogantes y retos del legislador. Revista Boliviana de Derecho, 23, 168-191. ISSN-e 2070-8157 [Consulta: 18 junio 2017]. Disponible en: http:/ / www.revistabolivianadederecho.com/index.php/rbd/revista-digital$\mathrm{pdf} /$ send/2-nuestras-publicaciones-revista-rbd/2777-rbd23

TRONCOSO REIGADA, A., 2009. Reutilización de información pública y protección de datos personales. Revista general de información y documentación, 19 (1), 243-264. ISSN 1132-1873 [Consulta: 17 junio 2017]. Disponible en: http://revistas.ucm.es/index.php/RGID/article/view/RGID0909110243A/ $\underline{9169}$

VÁZQUEZ DE CASTRO, E., 2012. Protección de datos personales, redes sociales y menores. Revista Aranzadi de derecho y nuevas tecnologías, 29, 21-60. ISSN 16960351 


\section{Referencias legislativas}

ESPAÑA, 1986. Ley Orgánica 3/1986, de 14 de abril, de medidas especiales en materia de salud pública (BOE núm. 102, de 29 de abril de 1986) [Consulta: 16 junio 2017]. Disponible en: http://www.boe.es/buscar/doc.php?id=BOE-A1986-10498

ESPAÑA, 1986. Ley 14/1986, de 25 de abril, General de Sanidad (BOE núm. 102, de 29 de abril de 1986) [Consulta: 15 junio 2017]. Disponible en: http://www.boe.es/buscar/doc.php?id=BOE-A-1986-10499

ESPAÑA, 1996. Ley Orgánica 1/1996, de 15 de enero, de Protección Jurídica del Menor, de modificación parcial del Código civil y de la Ley de Enjuiciamiento Civil (BOE núm. 15, de 17 de enero de 1996) [Consulta: 10 junio 2017]. Disponible en:

http://www.boe.es/buscar/doc.php?id=BOE-A-1996-1069

ESPAÑA, 1996. Real Decreto Legislativo 1/1996, de 12 de abril, por el que se aprueba el texto refundido de la Ley de Propiedad Intelectual, regularizando, aclarando y armonizando las disposiciones legales vigentes sobre la materia (BOE núm. 97, de 22 de abril de 1996) [Consulta: 15 mayo 2017]. Disponible en: http://www.boe.es/buscar/doc.php?id=BOE-A-1996-8930

ESPAÑA, 1999. Ley Orgánica 15/1999, de 13 de diciembre, de Protección de Datos de Carácter Personal (BOE núm. 298, de 14 de diciembre de 1999) [Consulta: 17mayo 2017]. Disponible en: http:/ / www.boe.es/buscar/doc.php?id=BOE-A-1999-23750

ESPAÑA, 2002. Ley 41/2002, de 14 de noviembre, básica reguladora de la autonomía del paciente y de derechos y obligaciones en materia de información y documentación clínica (BOE núm. 274, de 15 de noviembre de 2002) [Consulta: 03 junio 2017]. Disponible en: http://www.boe.es/buscar/doc.php?id=BOE-A-2002-22188

ESPAÑA, 2003. Ley 16/2003, de 28 de mayo, de Cohesión y Calidad del Sistema Nacional de Salud (BOE núm. 128, de 29 de mayo de 2003) [Consulta: 17 junio 2017]. Disponible en: http://www.boe.es/buscar/doc.php?id=BOEA-2003-10715

ESPAÑA, 2007. Ley 11/2007, de 22 de junio, de acceso electrónico de los ciudadanos a los Servicios Públicos (BOE núm. 150, de 23 de junio de 2007) [Consulta: 11 junio 2017]. Disponible en: http://www.boe.es/buscar/doc.php?id=BOE-A2007-12352

ESPAÑA, 2007. Ley 14/2007, de 3 de julio, de Investigación Biomédica (BOE núm. 159, de 4 de julio de 2007) [Consulta: 10mayo 2017]. Disponible en: http://www.boe.es/buscar/doc.php?id=BOE-A-2007-12945

ESPAÑA, 2007. Ley 37/2007, de 16 de noviembre, sobre reutilización de la información del sector público (BOE núm. 276, de 17 de noviembre de 
2007) [Consulta: 20mayo 2017]. Disponible en: http:/ / www.boe.es/buscar/doc.php?id=BOE-A-2007-19814

ESPAÑA, 2007. Ley 11/2007, de 26 de noviembre, reguladora del Consejo Genético, de protección de los derechos de las personas que se sometan a análisis genéticos y de los bancos de ADN bumano en Andalucía (BOE núm. 38, de 13 de febrero de 2008)[Consulta: 25mayo 2017]. Disponible en: http://www.boe.es/buscar/doc.php?id=BOE-A-2008-2491

ESPAÑA, 2007. Real Decreto 1720/2007, de 21 de diciembre, por el que se aprueba el Reglamento de desarrollo de la Ley Orgánica 15/1999, de 13 de diciembre, de protección de datos de carácter personal (BOE núm. 17, de 19 de enero de 2008) [Consulta: 11junio 2017]. Disponible en: http://www.boe.es/buscar/doc.php?id=BOE-A-2008-979

ESPAÑA, 2010. Real Decreto 3/2010, de 8 de enero, por el que se regula el Esquema Nacional de Seguridad en el ámbito de la Administración Electrónica (BOE núm. 25, de 29 de enero de 2010) [Consulta: 16 junio 2017]. Disponible en: http://www.boe.es/buscar/doc.php?id=BOE-A-2010-1330

ESPAÑA, 2011. Ley 33/2011, de 4 de octubre, General de Salud Pública (BOE núm. 240, de 5 de octubre de 2011) [Consulta: 17 junio 2017]. Disponible en: http://www.boe.es/buscar/doc.php?id=BOE-A-2011-15623

ESPAÑA, 2014. Real Decreto-ley 9/2014, de 4 de julio, por el que se establecen las normas de calidad y seguridad para la donación, la obtención, la evaluación, el procesamiento, la preservación, el almacenamiento y la distribución de células y tejidos humanos y se aprueban las normas de coordinación y funcionamiento para su uso en bumanos (BOE núm. 163, de 5 de julio de 2014) [Consulta: 10mayo 2017]. Disponible en: http://www.boe.es/buscar/doc.php?id=BOE-A-2014-7065

ESPAÑA, 2014. Ley 10/2014, de 29 de diciembre, de Salud de la Comunitat Valenciana (BOE núm. 35, de 10 de febrero de 2015) [Consulta: 12mayo 2017]. Disponible en: http://www.boe.es/buscar/doc.php?id=BOE-A-2015-1239

ESPAÑA, 2015. Ley 18/2015, de 9 de julio, por la que se modifica la Ley 37/2007, de 16 de noviembre, sobre reutilización de la información del sector público (BOE núm. 164, de 10 de julio de 2015) [Consulta: 12 junio 2017]. Disponible en: http://www.boe.es/buscar/doc.php?id=BOE-A-2015-7731

ESPAÑA, 2015. Ley Orgánica 8/2015, de 22 de julio, de modificación del sistema de protección a la infancia y a la adolescencia (BOE núm. 175, de 23 de julio de 2015) [Consulta: 05 junio 2017]. Disponible en: http://www.boe.es/buscar/doc.php?id=BOE-A-2015-8222

ESPAÑA, 2015. Ley 24/2015, de 24 de julio, de Patentes (BOE núm. 177, de 25 de julio de 2015) [Consulta: 14 junio 2017]. Disponible en: http:/ / www.boe.es/buscar/doc.php?id=BOE-A-2015-8328 
ESPAÑA, 2015. Ley 26/2015, de 28 de julio, de modificación del sistema de protección a la infancia y a la adolescencia (BOE núm. 180, de 29 de julio de 2015) [Consulta: 13 junio 2017]. Disponible en: http://www.boe.es/buscar/doc.php?id=BOEA-2015-8470

ESPAÑA, 2015. Ley 39/2015, de 1 de octubre, del Procedimiento Administrativo Común de las Administraciones Públicas (BOE núm. 236, de 2 de octubre de 2015) [Consulta: 15 junio 2017]. Disponible en: http://www.boe.es/buscar/doc.php?id=BOE-A-2015-10565

ESPAÑA, 2015. Real Decreto 951/2015, de 23 de octubre, de modificación del Real Decreto 3/2010, de 8 de enero, por el que se regula el Esquema Nacional de Seguridad en el ámbito de la Administración Electrónica (BOE núm. 264, de 4 de noviembre de 2015) [Consulta: 15mayo 2017]. Disponible en: http:/ /www.boe.es/buscar/doc.php?id=BOE-A-2015-11881

ESPAÑA, 2015. Real Decreto 1090/2015, de 4 de diciembre, por el que se regulan los ensayos clínicos con medicamentos, los Comités de Ética de la investigación con medicamentos y el Registro Español de Estudios Clínicos (BOE núm. 307, de 24 de diciembre de 2015) [Consulta: 13mayo 2017]. Disponible en:http:/ / www.boe.es/buscar/doc.php?id=BOE-A-2015-14082

ESPAÑA, 2015. Real Decreto 1091/2015, de 4 de diciembre, por el que se crea y regula el Registro Estatal de Enfermedades Raras (BOE núm. 307, de 24 de diciembre de 2015) [Consulta: 01 junio 2017]. Disponible en: http://www.boe.es/buscar/doc.php?id=BOE-A-2015-14083

ESPAÑA, 2017. Real Decreto 316/2017, de 31 de marzo, por el que se aprueba el Reglamento para la ejecución de la Ley 24/2015, de 24 de julio, de Patentes (BOE núm. 78, de 1 de abril de 2017) [Consulta: 16 junio 2017]. Disponible en: http://www.boe.es/buscar/doc.php?id=BOE-A-2017-3550

UNESCO, 2003. Declaración Internacional sobre los Datos Genéticos Humanos de 16 de octubre de 2003. [Consulta: 17 junio 2017]. Disponible en:http://portal.unesco.org/es/ev.php-

URL ID $=17720 \& U R L$ DO=DO TOPIC\&URL SECTION=201.html

UNIÓN EUROPEA, 2009. Recomendación del Consejo, de 8 de junio, relativa a una acción en el ámbito de las enfermedades raras. 2009/C 151/02. [Consulta: 19junio 2017]. Disponible en:http://eur-lex.europa.eu/legalcontent/ES/TXT/?uri=CELEX:32009H0703(02) 